\title{
SISTEM PENDUKUNG KEPUTUSAN PENILAIAN KINERJA STAF KANTOR BUPATI PRINGSEWU MENGGUNAKAN FUZZY MULTIPLE ATTIRIBUTE DECISION MAKING
}

\author{
${ }^{1)}$ Karlina, ${ }^{2)}$ Muhamad Muslihudin \\ ${ }^{1,2)}$ Prodi Sistem Informasi STMIK Pringsewu Lampung \\ Jl. Wismarini No. 09 Pringsewu - Lampung, \\ Telp. (0729) 22240 website: www.stmikpringsewu.ac.id \\ Email :karlina12906@gmail.com ${ }^{1)}$,muslih.udin@ymail.com ${ }^{2)}$
}

\begin{abstract}
Abstrak
Kabupaten yang berkembang dan semakin maju ditentukan oleh Sumber Daya Manusia yaitu staf yang mengelola. Tetapi sering kali dihadapkan oleh permasalahan bagaimana menilai kinerja staf yang baik. Permasalahan ini dapat diatasi dengan membuat suatu Sistem penilaian kinerja staf dengan mudah, cepat dan efektif. Metode Simple Additive Weighting dipilih karena metode ini menentukan nilai bobot untuk setiap atribut kemudian dilanjutkan dengan proses perangkingan yang alternatif terbaik dari sejumlah alternatif dalam hal ini alternatif yang dimaksud adalah Kinerja Staf berdasarkan kriteria yang telah ditentukan yaitu kesetian, prestasi kerja,tanggung jawab, ketaatan, kejujuran, kerja sama, prakarsa, kepemimpinan. hasil dari penelitian ini berbentuk sebuah sistem pendukung keputusan yang dapat mengolah data untuk penilaian kinerja staf terbaik menjadi pertimbangan yang valid. Berdasarkan hasil dari penelitian yang telah dilakukan terhadap hasil dari penelitian yang telah dilakukan terhadap empat alternatif yang di uji mewakili 5 karyawan di kantor Bupati pringsewu di peroleh hasil Karyawanl $V_{l}=85$ Karyawan $2 \quad V_{2}=75 \quad$ Karyawan $3 \quad V_{3}=38,5$ Karyawan4 $V_{4}=51$ Karyawan5 $V_{5}=57,75$, nilai terbesar dari penjumlahan matriks diatas adalah $V_{l}=85$ dengan demikian alternatif $V_{1}$ dapat disebut Staf yang bersangkutan dinyatakan memiliki kinerja yang memuaskan dan terbaik dalam proses kerja pada Kantor Bupati Pringsewu.
\end{abstract}

Kata Kunci : Sistem Pendukung Keputusan, Staf, Kinerja, Simple Additive Weighting

\subsection{Latar Belakang}

\section{PENDAHULUAN}

Dengan perkembangan Ilmu Pengetahuan dan Teknologi perkembangan dibidang pemerintahan saat ini cukup pesat salah satunya perubahan diwujudkannya tata kepemerintahan yang transparansi dan demokratis. Salah satu unsur penyelenggaraan pemerintahan yang perlu memperoleh perhatian dalam upaya reformasi ialah penataan aparatus pemerintah yang meliputi penataan kelembagaan birokrasi, system dan penataan manajemen sumber daya manusia(ASN).

Sumber daya Manusia merupakan faktor penting dalam Pemerintahan karena menentukan hasil dari suatu pekerjaan tersebut, Sumber Daya Manusia yang baik akan menghasilkan pekerjaan yang baik pula. Kinerja setiap orang dipengaruhi oleh aspek yang berbeda-beda. T.R Mitchell (1978:343) dalam Sedarmayanti (2001:51) menyatakan bahwa kinerja meliputi beberapa aspek, yaitu: (1) Kualitas Kerja, (2) Ketepatan, (3) Inisiatif, (4) Kemampuan, (5) Komunikasi. Pada penelitian ini penulis mencoba menerapkan metode Simple Additive Weighting untuk menentukan Penilaian kinerja staf di Kantor Bupati Pringsewu.

Dengan menerapkan metode Simple Additive Weighting terhadap objek Kinerja Staf di Kantor Bupati Pringsewu nantinya akan di peroleh sebuah metode penilaian kinerja staf dikantor bupati pringsewu. Dengan kreteria dan variabel yang ditentukan akan memudahkan dalam proses perbandingan hasil yang dicapai dengan aspek yang mempengaruhi kinerja staf yang berdampak pada Sumber Daya Manusia untuk mampu bersaing dengan Kaputen lainnya.

\section{LANDASAN TEORI}

\subsection{Konsep Sistem Pendukung Keputusan}

Michael S.Scott Morton (1970) Sistem Pendukung Keputusan adalah sistem informasi yang bertujuan untuk membantu manajemen puncak dalam mengambil keputusan yang tidak terstruktur, keputusan tidak terstruktur sifatnya tidak rutin disebut keputusan tidak terstruktur karena masalahnya tidak jelas, jalan keluarnya pun juga tidak jelas. Sistem Pendukung Keputusan merupakan suatu sistem interaktif yang membantu manajer dalam mengambil keputusan melalui penggunaan data dan model keputusan untuk meemecahkan masalahmasalah yang sifatnya semi terstruktur [1].

Sistem pendukung keputusan menurut efrain turban (2005:19) adalah sistem berbasis komputer interaktif, yang membantu para pengambil keputusan untuk menggunakan data dan bebagai model untuk memecahkan masalah tidak teratur. Menggunakan kombinasi dari model, teknik analisis dan pengambilan informasi sistem seperti membantu mengembangkan dan mengevaluasi alternatif yang sesuai. Menurut Kusrini (2007) sistem pendukung keputusan merupakan sistem informasi interaktif yang menyediakan informasi, pemodelan dan pemanipulasian data [2].

Efraim Turban (2001,P100), aplikasi sistem pendukung keputusan bisa dikomposisikan dengan subsistem berikut: 


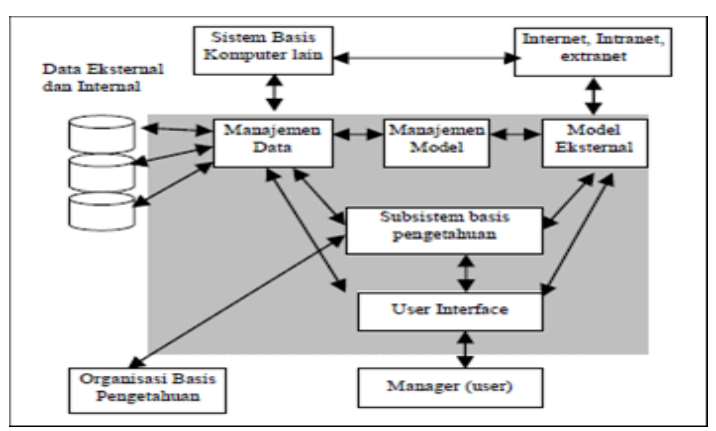

Gambar 1. Komponen SPK, Sumber : Turban, 2001:109[3]

\subsection{Definisi Karyawan}

Karyawan merupakan faktor pendukung dalam sebuah perusahaan atau isntansi, karena dengan adanya karyawan yang memiliki standar kualifikasi perusahaan maka produktivitas perusahaan pasti akan tetap terjaga dan semakin meningkat. Proses penilaian yang cepat dan akurat akan prestasi kinerja karyawan yang tepat(memenuhi kriteria yang diharapkan), dibutuhkan proses yang otomatisasi dengan menggunakan teknologi. Oleh karena itu kebutuhan sebuah sistem yang berbasis komputer dirasa sangat perlu guna memenuhi tuntutan akan kebutuhan informasi [4].

\subsection{Definisi Kinerja Karyawan}

Menurut Stolovitch and Kepps Kinerja adalah Seperangkat hasil yang dicapai dan merujuk pada tindakan pencapaian serta pelaksanaan sesuatu pekerjaan yang diminta.Menurut Mangkuprawira dan hubeis(2007:153). Kinerja Karyawan adalah hasil dari proses pekerjaan tertentu secara berencana pada waktu dan tempat dari karyawan serta organisasi bersangkutan. Kusriyanto (1991:3) dalam mangkunegara (2007:9) mendefinisikan kinerja karyawan sebagai perbandingan hasil yang dicapai dengan peran serta tenaga kerja persatuan waktu [4][5].

Kemudian Gomes (1995:195) mengemukakan kinerja karyawan sebagai ungkapan seperti output, efisiensi serta efektivitas sering dihubungkan dengan produktivitas. Mangkunegara (2007:9) mendefinisikan kinerja karyawan (prestasi karyawan) adalah hasilkerja secara kualitas dan kuantitas yang dicapai oleh seseorang karyawan dalam melaksankan tugasnya sesuai dengan tanggung jawab yang diberikan kepadanya.

\subsection{Fuzzy Multiple Attribute Decision Making}

Sri Kusuma Dewi (2013) Fuzzy Multiple Attribute Decision Making adalah suatu metode yang digunakan untuk mencari alternatif optimal dari sejumlah alternatif dengan kriteria tertentu[6]-[12]. Ada beberapa metode yang dapat digunakan untuk menyelesaikan masalah FMADM [13]:
a. Simple Additive Weighting method (SAW)
b. Weight Product (WP)
c. ELECTRE
d. Tehnique For Order Preference by Similarity to Ideal Solution (TOPSIS)
e. Analytic Hierarchy Process (AHP).

\section{PEMBAHASAN}

\subsection{Metode Simple Additive Weighting}

Simple Additive Weighting sering juga dikenal dengan istilah metode penjumlahan berbobot. Konsep dasar metode SAW adalah mencari penjumlahan terbobot dari rating kinerja pada setiap alternative dri semua atribut (fishburn, 1976). Metode SAW membutuhkan proses normalisasi matriks keputusan (x) ke suatu skala yang dapat diperbandingkan dengan semua rating alternative yang ada [14]-[17].

$$
\begin{array}{r}
\text { Diberikan } \quad \text { persamaan sebagai } \\
\mathrm{r}_{\mathrm{ij}}= \begin{cases}\frac{\mathrm{x}_{\mathrm{ij}}}{\operatorname{Max}_{\mathrm{ij}}} & \text { Jika } \mathrm{j} \text { atribut keuntungan (benefit) } \\
\frac{\operatorname{Min}_{\mathrm{i}} \mathrm{x}_{\mathrm{ij}}}{\mathrm{x}_{\mathrm{ij}}} & \text { Jika } \mathrm{j} \text { atribut biaya (cost) }\end{cases}
\end{array}
$$

Keterangan :

$\mathrm{rij}=$ rating kinerja ternormalisasi

$\operatorname{Max} X_{i j}=$ nilai maximum dari setiap baris dan kolom

Min $\mathrm{X}_{\mathrm{ij}}=$ nilai minimum dari setiap baris dan kolom

$\mathrm{X}_{\mathrm{ij}}=$ baris dan kolom matriks

Benefit $=$ jika nilai terbesar adalah terbaik

Cost $=$ jika nilai terkecil

Dengan $R_{i j}$ adalah ranting kinerja ternomalisasi dari alternative Ai pada atribut $\mathrm{Cj} ; \mathrm{I}=1,2, \ldots . \mathrm{m}$ dan $\mathrm{j}=1,2, \ldots . \mathrm{n}$ Nilai preferensi untuk setiap alternative $(\mathrm{Vi})$ diberikan sebagai :

$$
\nu_{i}=\sum_{j=1}^{n} w_{j} r_{i j}
$$

$\mathrm{V}_{\mathrm{i}}=$ nilai rangking untuk setiap alternatif

$\mathrm{W}_{\mathrm{j}}=$ nilai bobot dari setiap kriteria

$\mathrm{r}_{\mathrm{ij}}=$ rating kinerja ternormalisasi

Nilai Vi yang lebih besar mengindifikasikan bahwa alternative Ai lebih terpilih.

Langkah penyelesaian Simple Additive Weighting (SAW) [18]:

1. Menentukan Alternatif, yaitu Ai

2. Menentukan kriteria-kriteria yang akan dijadikan acuan dalam pengambilan keputusan, yaitu $\mathrm{Ci}$.

3. Menentukan rating kecocokan setiap alternatif pada setiap kriteria.

4. Membuat matriks keputusan berdasarkan kriteria (Ci),kemudian melakukan normalisasi matriks berdasarkan persamaan yang disesuaikan dengan jenis atribut (atribut keutungan ataupun atribut biaya) sehingga diperoleh matriks ternormalisasi r.

5. Hasil akhir diperoleh dari hasil perangkingan yaitu penjumlahan dari perkalian matriks ternormalisasi $\mathrm{R}$ dengan vector bobot sehingga diperoleh nilai terbesar yang dipilih sebagai alternatif terbaik (Ai) sebagai solusi.

\subsection{Kriteria Pembobotan}

Bobot dan kriteria dalam Penilaian Kinerja Staf di Kantor Bupati Pringsewu. Tabel 1 Kriteria Adapun kriteria yang dinilai pada alternatif dengan bobot nilainya adalah : 


\begin{tabular}{|l|l|l|}
\hline Kriteria & Keterangan & Nilai \\
\hline C1 & Kesetiaan & 10 \\
\hline C2 & Prestasi Kerja & 15 \\
\hline C3 & Tanggung Jawab & 15 \\
\hline C4 & Ketaatan & 10 \\
\hline C5 & Kejujuran & 10 \\
\hline C6 & Kerja Sama & 10 \\
\hline C7 & Prakarsa & 15 \\
\hline C8 & Kepemimpinan & 15 \\
\hline & & $\mathbf{1 0 0}$ \\
\hline
\end{tabular}

Tabel 2 Alternatif

Sedangkan variabel pada pembobotan adalah :

\begin{tabular}{|l|l|}
\hline Variabel & Keterangan \\
\hline A1 & Karyawan1 \\
\hline A2 & Karyawan2 \\
\hline A3 & Karyawan3 \\
\hline A4 & Karyawan4 \\
\hline A5 & Karyawan5 \\
\hline
\end{tabular}

Tabel 3 Bobot Nilai

Dan Penjelasan bobot nilai dari Penilaian adalah :

\begin{tabular}{|l|l|}
\hline \multicolumn{1}{|c|}{ Bobot } & Nilai \\
\hline Sangat Baik (SB) & 5 \\
\hline Baik(B) & 4 \\
\hline Cukup(C) & 3 \\
\hline Kurang(K) & 2 \\
\hline Sangat Kurang (SK) & 1 \\
\hline
\end{tabular}

Tabel 7 Pembobotan Alternatif Tiap kriteria

Pada tabel ini didapatkan nilai setiap alternatif dengan Bobot nilai tiap kriteria sebagai berikut :

\begin{tabular}{|c|c|r|r|r|r|r|}
\hline \multirow{2}{*}{$\begin{array}{c}\text { N } \\
\text { o }\end{array}$} & \multirow{2}{*}{ Kriteria } & \multicolumn{5}{|c|}{ Karyawan } \\
\cline { 3 - 7 } & & A1 & A2 & A3 & A4 & A5 \\
\hline 1 & C1 & 5 & 2 & 5 & 5 & 2 \\
\hline 2 & C2 & 3 & 3 & 1 & 1 & 1 \\
\hline 3 & C3 & 2 & 4 & 2 & 2 & 1 \\
\hline 4 & C4 & 3 & 3 & 3 & 1 & 1 \\
\hline 5 & C5 & 2 & 4 & 4 & 2 & 4 \\
\hline 6 & C6 & 3 & 3 & 4 & 3 & 4 \\
\hline 7 & C7 & 5 & 2 & 2 & 2 & 5 \\
\hline 8 & C8 & 4 & 2 & 2 & 2 & 2 \\
\hline
\end{tabular}

Dalam pengambilan keputusan peneliti harus dapat memberikan bobot, berdasarkan tingkatan kualitas setiap masing masing kriteria yang dibutuhkah sebagi berikut: Vektor bobot $X(\mathbf{1 0}, 15,15,10,10,10,15,15)$

Membuat matriks keputusan $\mathrm{x}$, dapat dibuat dari tabel kecocokan sebagai berikut:

$$
X=\left\{\begin{array}{lllll}
5 & 2 & 5 & 5 & 2 \\
3 & 3 & 1 & 1 & 1 \\
2 & 4 & 2 & 2 & 1 \\
3 & 3 & 3 & 1 & 1 \\
2 & 4 & 4 & 2 & 4 \\
3 & 3 & 4 & 3 & 4 \\
5 & 2 & 2 & 2 & 2 \\
4 & 2 & 2 & 2 & 2
\end{array}\right.
$$

Pertama kita lakukan normalisasi matriks $\mathrm{x}$ untuk menghitung masing-masing kriteria berdasarkan kriteria sebagai berikut pada Kolom C dibagi oleh nilai maksimal kolom C:

$$
\text { A1 }
$$

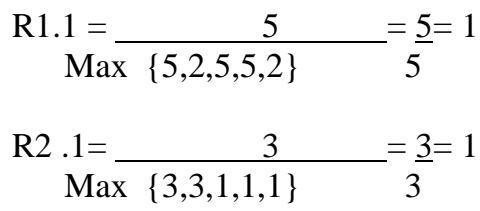$$
\mathrm{R} 3.1=\frac{2}{\operatorname{Max}\{2,4,2,2,1\}}=\underline{2}=0,5
$$$$
\mathrm{R} 4.1=\frac{3}{\operatorname{Max}\{3,3,3,1,1\}}=\underline{3}=1
$$$$
\mathrm{R} 5.1=\frac{2}{\operatorname{Max}\{2,4,4,2,4\}}=\frac{2}{4}=0,5
$$$$
\text { R6. } 1=\frac{3}{\operatorname{Max}\{3,3,4,3,4\}}=\underline{3}=0,75
$$$$
\mathrm{R} 7.1=\frac{5}{\operatorname{Max}}=\frac{5}{5}=1
$$

$$
\mathrm{R} 8.1=\frac{4}{\operatorname{Max}\{4,2,2,2,2\}}=\underline{4}=1
$$$$
\text { A2 }
$$$$
\mathrm{R} 1.2=\frac{2}{\operatorname{Max}\{5,2,5,5,2\}}=\underline{2}=0,4
$$$$
\mathrm{R} 2.2=\frac{3}{\operatorname{Max}\{3,3,1,1,1\}}=\underline{3}=1
$$$$
\mathrm{R} 3.2=\frac{4}{\operatorname{Max}\{2,4,2,2,1\}}=\underline{4}=1
$$$$
\mathrm{R} 4 \underset{\operatorname{Max}}{.2} \frac{3}{\{3,3,3,1,1\}}=\underline{3}=1
$$$$
\mathrm{R} 5.2=\frac{4}{\operatorname{Max}\{2,4,4,2,4\}}=\underline{4}=1
$$$$
\text { R6.2 }=\frac{3}{\operatorname{Max}\{3,3,4,3,4\}}=\underline{3}=0,75
$$$$
\text { R7.2 }=\frac{2}{\operatorname{Max}\{5,2,2,2,5\}}=\frac{2}{5}=0,4
$$$$
\mathrm{R} 8.2=\frac{2}{\operatorname{Max}\{4,2,2,2,2\}}=\underset{4}{4}=0,5
$$
A3
$\mathrm{R} 1.1=$ $\operatorname{Max}\{5,2,5,5,2\} \quad 5$ $5 \quad=\underline{5}=1$
$\mathrm{R} 2.1=$ $=\underline{1}=0,3$ 
$\operatorname{Max}\{3,3,1,1,1\} \quad 3$

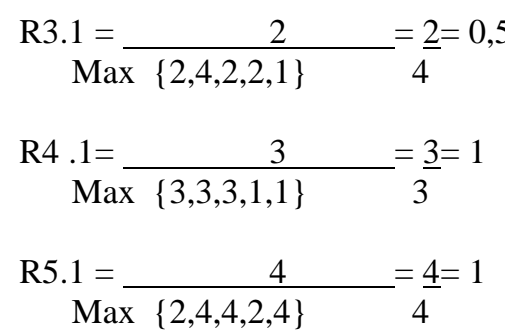

$\operatorname{R} 6.1=\frac{4}{\operatorname{Max}\{3,3,4,3,4\}}=\frac{4}{4}=1$

$\mathrm{R} 7.1=\frac{2}{\operatorname{Max}\{5,2,2,2,5\}}=\frac{2}{5}=0,4$
$\mathrm{R} 8.1=\frac{2}{\operatorname{Max}\{4,2,2,2,2\}}=\underset{4}{2}=0,5$

A4

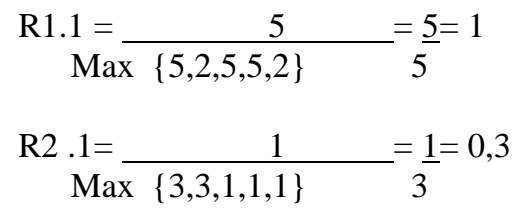

R3. $1=\frac{2}{\text { Max }\{2,4,2,2,1\}}=\underline{2}=0,5$
R4 .1=
$\quad \operatorname{Max}\{3,3,3,1,1\}$

$\mathrm{R} 5.1=\frac{2}{\operatorname{Max}\{2,4,4,2,4\}}=\frac{2}{4}=0,5$

$\mathrm{R} 6.1=\frac{3}{\operatorname{Max}\{3,3,4,3,4\}}=\underline{3}=0,75$
$\mathrm{R} 7 \cdot 1=\frac{2}{\operatorname{Max}}=\frac{2}{5}=0,4$
$\operatorname{R} 8.1=\frac{2}{\operatorname{Max}\{4,2,2,2,2\}}=\frac{2}{4}=0,5$

A5
$\mathrm{R} 1.1=\frac{2}{\operatorname{Max}\{5,2,5,5,2\}}=\frac{2}{5}=0,4$
$\mathrm{R} 2.1=\frac{1}{\operatorname{Max}\{3,3,1,1,1\}}=\underline{1}=0,3$

R3.1 $=\frac{1}{\operatorname{Max}\{2,4,2,2,1\}}=\frac{1}{4}=0,25$

$\mathrm{R} 4.1=\frac{1}{\operatorname{Max}\{3,3,3,1,1\}}=\underline{1}=0,3$

$\mathrm{R} 5.1=\frac{4}{\operatorname{Max}\{2,4,4,2,4\}}=\frac{4}{4}=1$

$$
\begin{aligned}
& \text { R6. } 1=\frac{4}{\operatorname{Max}\{3,3,4,3,4\}}=\frac{4}{4}=1 \\
& \text { R7.1 }=\frac{5}{\operatorname{Max}\{5,2,2,2,5\}}=\underline{5}=1 \\
& \mathrm{R} 8.1=\frac{2}{\operatorname{Max}\{4,2,2,2,2\}}=\underline{2}=0,5
\end{aligned}
$$

Kedua, membuat normalisasi matriks Y yang diperoleh dari hasil matriks $\mathrm{X}$ sebagai berikut:

$\left\{\begin{array}{ccccc}1 & 0,4 & 1 & 1 & 0,4 \\ 1 & 1 & 0,3 & 0,3 & 0,3 \\ 0,5 & 1 & 0,5 & 0,5 & 0,25 \\ 1 & 1 & 1 & 0,3 & 0,3 \\ 0,5 & 1 & 1 & 0,5 & 1 \\ 0,75 & 0,75 & 1 & 0,75 & 1 \\ 1 & 0,4 & 0,4 & 0,4 & 1 \\ 1 & 0,5 & 0,5 & 0,5 & 0,5\end{array}\right\}$

\section{Perhitungan Alternatif}

Dengan Mengalikan setiap kolom di tabel tersebut dengan bobot kriteria yang telah dideklarasikan.

Dengan Menggunakan Persamaan:

$$
V_{i}=\sum_{j=1}^{n} w_{j} r_{i j}
$$

$\mathbf{V}_{1}=(1 \times 10)+(1 \times 15)+(0,5 \times 15)+(1 \times 10)+(0,5 \times 10)+$ $(0,75 \times 10)+(1 \times 15)+(1 \times 15)$

$=(10+15+7,5+10+5+7,5+15+15)=\mathbf{8 5}$

$\mathbf{V}_{2}=(0,4 \times 10)+(1 \times 15)+(1 \times 15)+(1 \times 10)+(1 \times 10)+$ $(0,75 \times 10)+(0,4 \times 15)+(0,5 \times 15)$

$=(4+15+15+10+10+7,5+6+7,5)=\mathbf{7 5}$

$\mathbf{V}_{3}=(1 \times 10)+(0,3 \times 15)+(0,5 \times 15)+(1 \times 10)+(1 \times 10)+$ $(1 \times 10)+(0,4 \times 15)+(0,5 \times 15)$

$=(10+4,5+7,5+1+1+1+6+7,5)=\mathbf{3 8 , 5}$

$\mathbf{V}_{4}=(1 \times 10)+(0,3 \times 15)+(0,5 \times 15)+(0,3 \times 10)+(0,5 \times$ $10)+(0,75 \times 10)+(0,4 \times 15)+(0,5 \times 15)$

$=(10+4,5+7,5+3+5+7,5+6+7,5)=\mathbf{5 1}$

$$
\begin{aligned}
\mathbf{V}_{\mathbf{5}}= & (0,4 \times 10)+(0,3 \times 15)+(0,25 \times 15)+(0,3 \times 10)+(1 \times \\
& 10)+(1 \times 10)+(1 \times 15)+(0,5 \times 15) \\
= & (10+15+7,5+10+5+7,5+15+15)=\mathbf{5 7 , 7 5}
\end{aligned}
$$

Dari perkalian matriks di $\mathrm{X} * \mathrm{Y}$ maka didapatkan hasil sebagai berikut : $\quad V_{1}=85 \quad V_{2}=75 \quad V_{3}=38,5 \quad V_{4}=51$ $\mathbf{V}_{\mathbf{5}} \mathbf{5 7 , 7 5}$, nilai terbesar dari penjumlahan matriks diatas adalah $\mathrm{V}_{1}=85$ 
Berdasarkan data diatas dapat digambarkan dengan grafik untuk menarik kesimpulan atau hasil dari perhitungan penilaian kinerja staf di Kantor Bupati Pringsewu sebagai berikut :

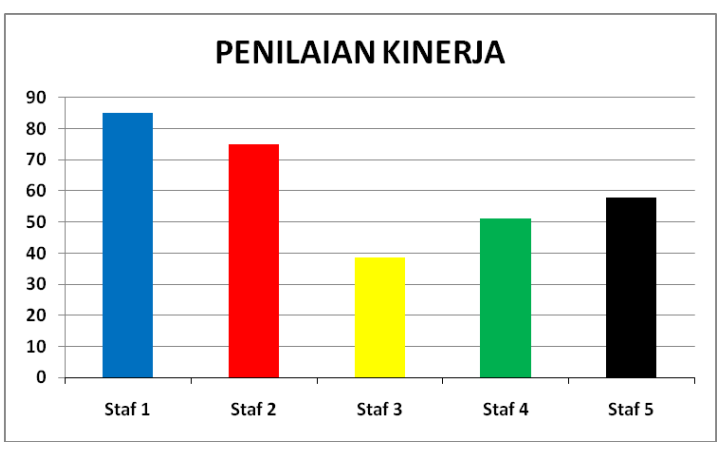

dengan demikian alternatif $\mathrm{V}_{1}$ dapat disebut Staf yang bersangkutan dinyatakan memiliki kinerja yang memuaskan dan terbaik dalam proses kerja pada Kantor Bupati Pringsewu.

\section{KESIMPULAN}

Dari hasil pembahasan permasalahan diatas dapat di ambil sebuah kesimpulan bahwa pengambilan keputusan penilaian Kinerja Staf di Kantor Bupati Pringsewu dapat menggunakan metode simple additive weighting dengan menggunakan kreteria Kesetiaan, Prestasi Kerja,Tanggung Jawab, Ketaatan Kejujuran, Kerja Sama, Prakarsa dan Kepemimpinan. Berdasarkan lima variabel yang di uji yang mewakili 5 Karyawan di Kabupaten Pringsewu di peroleh hasil Karyawan1, $\mathrm{V}_{1}=85$ Karyawan2 $\quad \mathrm{V}_{2}=75$ Karyawan3 $\quad \mathrm{V}_{3}=38,5$ Karyawan4 $\mathrm{V}_{4}=51$ Karyawan5 $\mathrm{V}_{5}=57,75$, nilai terbesar dari penjumlahan matriks diatas adalah $\mathrm{V}_{1}=85$ dengan demikian alternatif $\mathrm{V}_{1}$ dapat disebut dengan Kinerja Staf yang memuaskan dan terbaik dalam proses kerja pada Kantor Bupati Pringsewu.

\section{Daftar Pustaka}

[1] E. Turban, J. E. Aronson, and T.-P. Liang, "Decision Support Systems and Intelligent Systems," Decis. Support Syst. Intell. Syst., vol. 7, p. $867,2007$.

[2] N. T. Hartanti, K. Kusrini, and A. Amborowati, "Sistem Pendukung Keputusan Untuk Menentukan Program Keahlian di SMK Syubbanul Wathon Magelang," Konf. Nas. Sist. Inform. 2015, pp. 910, 2015.

[3] E. Turban, R. Sharda, and D. Delen, Decision Support and Business Intelligence Systems. Chapter 6 Artificial Neural Networks for Data Mining, vol. 8th. 2007.

[4] S. Zulkifli, "Decision Support System Pemberian Bonus Tahunan Pada Karyawan Berdasarkan Kinerja Karyawan Menggunakan Metode Simple Additive Weighting ( Study Kasus : Stmik Pringsewu )," J. TAM ( Technol. Accept. Model ), vol. 7, pp. 67-73, 2016.

[5] S. Mukodimah, M. Muslihudin, and A. Maseleno,
"Implementasi Weighted Product Untuk Mengukur Indeks Kinerja Kepala Desa Di Kecamatan Pringsewu," KNSI, pp. 23-40, 2018.

[6] L. Muhamad Muslihudin, "Implementasi Fuzzy Multiple Attribute Decision Making Menggunakan Metode Simple Additive Weighting Untuk Diagnosa Awal Gangguan Pada Masa Kehamilan," in KNSI 2016, 2016, pp. 11-13.

[7] S. H. Hanifa, Muhamad Muslihudin, "Sistem Pendukung Keputusan Menentukan Besar Gaji Untuk Guru Honorer Di Kabupaten Pesawaran Menggunakan Metode Fuzzy SAW," Jurtek IST Akprind Yogyakarta, vol. 9, no. 2, pp. 83-88, 2016.

[8] R. Wati, A. Irfan, and I. P. Sari, "Penerapan Analisis Gap Pada Sistem Pendukung Keputusan Kabupaten Pringsewu Untuk Kenaikan Jabatan,' in SNif, 2015, pp. 232-245.

[9] M. Muslihudin and F. Noviarti, Tri, "Sistem Pengambilan Keputusan Perankingan Wilayah Endemik Demam Berdarah Di Kabupaten Tanggamus," Semnasteknomedia, vol. 6, no. 1, pp. 7-12, 2018.

[10] Y. Sugiyanto, M. Muslihudin, and F. Satria, "Sistem Pakar Diagnosis Kualitas Bibit Kambing PE ( Peranakan Ettawah ) Menggunakan Image Prossesing Berbasis Website," SEMNASTEKNOMEDIA, vol. 6, no. 2014, p. 2.96, 2018.

[11] U. Lestari and M. Targiono, "Sistem Pendukung Keputusan Klasifikasi Keluarga Miskin Menggunakan Metode Simple Additive Weighting (SAW) Sebagai Acuan Penerima Bantuan Dana Pemerintah (Studi Kasus: Pemerintah Desa Tamanmartani, Sleman)," J. TAM ( Technol. Accept. Model ), vol. 8, no. 2, pp. 70-78, 2017.

[12] M. Muslihudin, F. Triananingsih, and L. Anggraei, "Pembuatan Model Penilaian Indeks Kinerja Dosen Menggunakan Metode Fuzzy Simple Additive Weighting," SEMNASTEKNOMEDIA, vol. 5, no. 1, pp. 25-30, 2017.

[13] S. Kusumadewi, S. Hartati, A. Harjoko, and Retanto Wardoyo, Fuzzy Multi-Attribute Decision Making (Fuzzy MADM). Yogyakarta: Graha Ilmu, 2013.

[14] R. Irviani, I. Dinulhaq, D. Irawan, R. Renaldo, and A. Maseleno, "Areas Prone of the Bad Nutrition based Multi Attribute Decision Making with Fuzzy Simple Additive Weighting for Optimal Analysis," Int. J. Pure Appl. Math., vol. 118, no. 7, pp. 589596, 2018.

[15] S. Mukodimah, M. Muslihudin, A. Andoyo, S. Hartati, and A. Maseleno, "Fuzzy Simple Additive Weighting and its Application to Toddler Healthy Food," Int. J. Pure Appl. Math., vol. 118, no. 7, pp. $1-7,2018$.

[16] M. Muslihudin, A. Latif, S. Ipnuwati, R. Wati, and A. Maseleno, "A Solution to Competency Test Expertise of Engineering Motorcycles using Simple Additive Weighting Approach," Int. J. 
Pure Appl. Math., vol. 118, no. 7, pp. 261-267, 2018.

[17] A. Alinezhad, A. Amini, and A. Alinezhad, "Sensitivity analysis of simple additive weighting method (SAW): the results of change in the weight of one attribute on the final ranking of alternatives," J. Ind. Eng., 2009.

[18] A. M. Muhammad Muslihudin, Rita Irviani, Prayugo Khoir, "Decision Support System Level Economic Classification Of Citizens Using Fuzzy Multiple Attribute Decision Makin," in ICCSE, 2017, pp. 1-75. 